\title{
Temporal properties of memory for speech in preschool children
}

\author{
NELSON COWAN \\ University of Missouri, Columbia, Missouri \\ and \\ LUANNE KIELBASA \\ University of Massachusetts, Amherst, Massachusetts
}

\begin{abstract}
The ability of four-year-old children to remember syllables was investigated, both to determine the temporal properties of memory for speech in subjects who do not use sophisticated retention strategies, and to determine what speech memory is available in the late preschool period. In Experiments 1 and 2, children were to remember pairs of nonsense syllables for 5, 10, 15, or 20 sec filled with a silent, manual task. In both experiments there was an apparent decay of one type of speech memory across 10-15 sec. In Experiment 2, strong interference was obtained when there was a final speech suffix item. An additional phase of this experiment verified that children cannot rehearse during the postlist period. However, in Experiments 3 and 4, suffix effects were not obtained with adult subjects in similar tasks. The results suggest that memory for speech persists for at least $10 \mathrm{sec}$ even in preschool children, but that adults, unlike preschool children, engage in an additional type of speech coding that increases the resistance of memory to speech interference.
\end{abstract}

Little is known about the temporal properties of preschool children's memory for speech. Yet there are important theoretical and practical reasons to investigate this memory. On theoretical grounds, such research may contribute to an understanding of strategy-dependent versus strategy-independent or "structural" components of memory. Past research suggests that young children do not use sophisticated memorization strategies, such as rehearsal, to encode and retain verbal material (Flavell, Beach, \& Chinsky, 1966; Kail \& Hagen, 1982). Consequently, by using preschool children, it may be possible to obtain an index of structural components of memory, relatively free of strategic processing. The present research both examines details of the speech coding deficiency in preschool children and uses it to examine structural aspects of speech memory. The practical reason to examine memory for speech in preschool children is that it is intrinsically involved in early language learning (Kuczaj, 1979; Tallal, Stark, Kallman, \& Mellits, 1981) and in beginning reading (Bradley \& Bryant, 1983). Memory for speech is clearly necessary, for example, for the child to compare his or her speech to a prior model or to learn

This research was supported by NIH Grant No. 1-R23-HD18698-01 awarded to the senior author. We thank Pearlie Pitts and Cristy Cartwright for assistance; Jean Ispa, Teresa Daly, Arthur Glenberg, Alice Healy, Priscilla Roth, Charles Clifton, Marvin Daehler, Nancy Myers, Tim Salthouse, and an anonymous reviewer for helpful comments on earlier drafts; and the University of Massachusetts Child Study Center and parents for making the study possible.

Send reprint requests to Nelson Cowan, Department of Psychology, University of Missouri, 210 McAlester Hall, Columbia, MO 65211. letter-to-sound correspondences. It is important to learn the temporal limits of such speech comparison processes.

An impetus for the present research is adult research (O. C. Watkins \& M. J. Watkins, 1980; M. J. Watkins \& Todres, 1980) that suggests that adults retain memory for speech for at least $20 \mathrm{sec}$. These studies focused on auditory sensory or "echoic" memory, which generally has been thought to persist for at most a few seconds (see Cowan, 1984, and Crowder, 1983, for reviews). However, the possibility remained that these shorter estimates of echoic memory were contaminated by other mental processes. In particular, subjects might quickly construct a modality-independent representation of the stimulus that obscures any further evidence of a modality-specific auditory memory. To eliminate this problem, the Watkinses used various means to prevent subjects from engaging in processing that could result in modality-independent forms of memory. Under these circumstances, a longer-lasting, auditory-modality-specific memory was observed.

In experiments with the suffix effect, subjects typically must remember a list of spoken words followed by a final interfering or "suffix" item. The greater the acoustic similarity between the list items and the suffix, the more interference is obtained (Crowder \& Morton, 1969; Morton, Crowder, \& Prussin, 1971). Ordinarily, in order for this differential interference to be obtained, the suffix must be presented within several seconds of the list (Crowder, 1971). However, M. J. Watkins and Todres (1980) found that when subjects were required to perform a silent distractor task between the list and the suffix, there was more interference from a speech suffix than from a 
control (tone) suffix, even with a postlist delay of $20 \mathrm{sec}$. Presumably, the distractor task prevented subjects from forming a modality-independent, interference-resistant memory of the list items.

However, the exact interpretation of this finding has been questioned in several subsequent studies. Penney (1985; p. 243) suggested that the memory observed after $20 \mathrm{sec}$ required a strategic mechanism, but that this memory was not eliminated by the special methods that the Watkinses used. Balota and Duchek (in press) found that the suffix effect was voice-specific (i.e., there was more interference when the same speaker produced the list and suffix) with an immediate suffix, but not with a suffix presented after a 20 -sec distractor task. Thus, there does seem to be a memory for speech that persists for $20 \mathrm{sec}$ or more in adults, although the detailed characteristics of this memory are uncertain.

The present research makes use of the general observation that preschool children do not use retention strategies as adults do. Experiment 1 introduces a methodology to examine the decay of memory for speech across a 20-sec poststimulus period in 4-year-old children. In Experiment 2 , a suffix is included after the delay period in this task. Moreover, a subsequent phase of that experiment demonstrates that the children were unable to rehearse aloud. In Experiments 3 and 4, similar tasks are used with adult subjects in order to provide a comparison with which to interpret the results of the preschool experiments.

\section{EXPERIMENT 1}

The spoken stimuli for the present study were nonsense syllables rather than words, which should eliminate any contribution of semantic memory. Performance levels within pilot research led to the decision to include two monosyllables on every trial. The syllables were followed by a variable delay period filled with a silent, manual dis- tractor task intended to maintain the child's quiet attention and discourage any strategic processing, without causing auditory-modality-specific or speech-related interference. Finally, after this delay, a series of pictures were presented, some of which had names that rhymed with the spoken syllables and served as the appropriate responses. The child was to silently point to the rhyming pictures rather than the other pictures, which served as foils. For example, in one trial the subject was instructed to "find things that sound like gock and foon," the correct items being a sock and a spoon.

\section{Method}

Subjects. The subjects were normal preschool children from lower-middle- to upper-middle-class homes, between the ages of 4 years, 0 months and 5 years, 0 months. Because all of the results of interest consisted of differences between conditions, the sensitivity of the experiment was protected by excluding subjects who performed below $40 \%$ or above $90 \%$ correct (chance $=33 \%$ ). Seven subjects did not meet this criterion. Two others were excluded because they did not complete the session. The final sample consisted of 48 children ( 24 male, 24 female) with a mean age of 4 years, 6 months ( $S D=1.3$ months).

Materials. There was one set of pictures for a training phase of the experiment, and another set for the actual test session. Each picture was drawn in color on a $10-\mathrm{cm}$ square card, and the pictures were mounted three to a page on $21.6 \times 27.9 \mathrm{~cm}(8.5 \times 11 \mathrm{in}$.) photograph album pages. Two pages were used on each trial, and each page contained one correct item and two foils. However, in order to control for the possibility that children might prefer certain items over others, there were three alternative sets of syllabic stimuli that could be used with the same picture sets. These alternative syllable sets were used with three different groups of subjects. On every page of three pictures, each picture was the correct item rhyming with a syllable heard by only one group of subjects. The syllables used in the test phase for the three groups and the corresponding pictured items are shown in Table 1.

Procedure. Subjects were tested individually in a quiet room. The child was introduced to the procedure one step at a time in the training phase. The task was to silently point to pictures whose names sounded like the syllables that were spoken by the experimenter. For the first training trial, the child heard syllables rhym-

Table 1

Pictured Items and Rhyming Syllables Used in Experiments 1-3

\begin{tabular}{llllllll}
\hline Item & Rhyme & Item & Rhyme & Item & Rhyme & Item & Rhyme \\
\hline horse & lorse (a) & bread & ked (b) & bed & ged (c) & knife & kife (a) \\
hat & lat (b) & truck & nuck (c) & duck & nuck (b) & worm & gurm (b) \\
shell & mell (c) & ball & jall (a) & dog & shog (a) & fence & lence (c) \\
dress & tress (c) & top & lop (c) & nail & zail (a) & book & sook (c) \\
fork & vork (a) & boat & foat (a) & cake & dake (c) & fox & mox (a) \\
road & pode (b) & car & lar (b) & brush & sush (b) & tent & zent (b) \\
lamp & samp (b) & mouse & gouse (a) & frog & mog (b) & box & mox (c) \\
cat & zat (a) & pipe & nipe (c) & door & noor (a) & roof & foof (b) \\
tree & ree (c) & soup & moop (b) & man & lan (c) & cup & rup (a) \\
plate & sate (a) & bear & vare (c) & fish & bish (c) & glove & buv (a) \\
sun & kun (c) & cow & zow (b) & house & nouse (b) & bird & sird (c) \\
shoe & voo (b) & drum & prum (a) & boy & loy (a) & belt & velt (b) \\
\hline
\end{tabular}

Note-Sets of three items were presented together on a single page. Reading the sets vertically, two consecutive sets were used together in a trial. The letters in parentheses indicate which group of subjects $(a, b$, or $c)$ received each spoken syllable. 
ing with each of the three pictures on a page (bell, clown, thumb) in turn. In the remainder of the experiment, two syllables and two pages of pictures were used on each trial. On the second trial within training, the subject was permitted to respond to the first syllable before the second syllable was presented. (The syllables rhymed with train and pear). This trial was then repeated, using the method to be used throughout the experiment: the two spoken syllables were presented together and then the response pages were presented one at a time. On each trial, the pair of syllables was repeated twice at the rate of approximately one syllable per second.

Pages of pictures were always presented one at a time, either in the same order in which the spoken syllables were presented (forward order), or in the reverse (backward) order. In the training trials mentioned above, a forward order of pictures was used, but in the next training trial, a backward order was used (with syllables that rhymed with sock and spoon).

Next the manual imitation task to be used during the postlist silent intervals was introduced. The experimenter demonstrated hand or arm motions on each trial (e.g., holding one elbow, touching the left and right hand together, pointing to both ears, or wiggling a thumb). Each motion was held until the subject attempted to imitate it, whereupon the experimenter modified the motion in some way (at a maximum rate of 0.5 motions per second, which the children usually could maintain). To incorporate this imitation task into the memory task, the previous trial was repeated with a 6 -sec imitation-filled delay between the syllables and pictures. A silent electronic timer was started immediately after the last list item, and the first picture sheet was presented immediately after the delay period.

The remainder of the training phase included three more trials with a 6-sec delay, with backward, forward, and backward picture orders, respectively. The spoken syllables in these trials rhymed with horn and hose, deer and whale, and pie and doll, respectively. Few problems arose during training.

In the test phase the same procedure was used, but with postlist delays of 5, 10, 15, and $20 \mathrm{sec}$. Each subject received four trials with a forward order of picture presentation and four trials with a backward order, with one trial at each delay interval. Half of the subjects received the forward picture order for the first four trials and then the backward order, whereas the other half received the backward order of pictures first. For each subject, the four delay intervals were ordered according to one row of a Latin square. The same Latin square order of delays was used for trials with the forward and backward picture orders. After each trial, the subject was rewarded with a colored sticker that was used throughout the session to complete a line drawing.

\section{Results and Discussion}

The mean percentages of correct picture selections were entered into an ANOVA with syllable serial position (2), delay (4), and picture presentation order (2) as factors. There was a significant advantage for items in the last (i.e., second) serial position $[F(1,45)=9.11, p<.005$, SEM $=2.7 \%]$, and there was a significant effect of delay $[F(3,135)=4.85, p<.004, \mathrm{SEM}=3.4 \%]$. The interaction of serial position $\times$ delay was not significant $[F(3,135)=1.56, p>.2]$. Means at the two serial positions were $59.4 \%$ and $72.9 \%$, respectively, with a 5 sec delay, $62.5 \%$ and $63.5 \%$ with a 10 -sec delay, $46.9 \%$, and $56.3 \%$ with a 15 -sec delay, and $40.6 \%$ and $63.5 \%$ with a $20-\mathrm{sec}$ delay. No other effect of this analysis approached significance. The effect of delay is also depicted in Figure 1. In the figure, it can be seen that performance levels decreased across the first $15 \mathrm{sec}$ of the delay period.

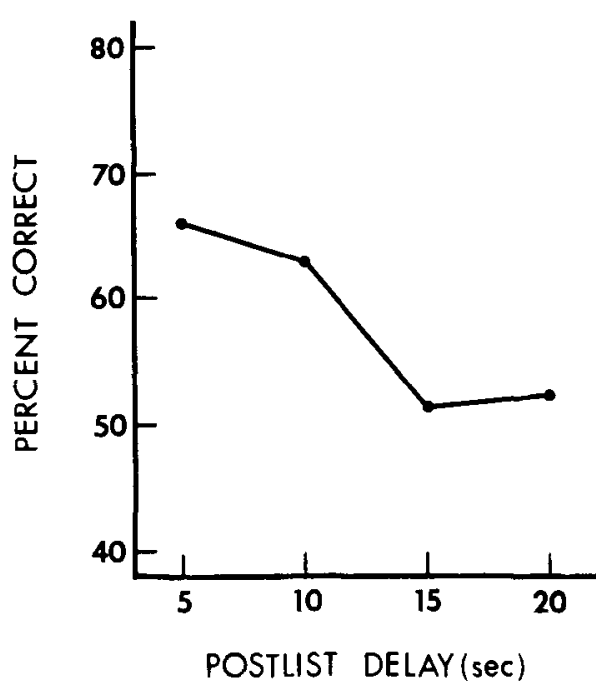

Figure 1. Percentage of correct picture selection at each delay in Experiment 1.

This finding suggests that there was a transient source of memory that decayed within about $15 \mathrm{sec}$ after the spoken list. However, this conclusion would be strengthened by a replication of the delay effect. Experiment 2 was conducted to provide this replication, and also to determine how this syllabic memory would be affected by spoken interference. The paradigm of Experiment 1 was repeated, but with an interfering suffix item at the end of the postlist delay period. Finally, following the main task within Experiment 2, an overt rehearsal training phase was included for half of the subjects in order to help assess the assumption that preschool children did not engage in strategic maintenance of memory during the postlist delay periods.

\section{EXPERIMENT 2}

\section{Method}

Subjects. The subjects were normal children from lower-middleto upper-middle-class homes, between the ages of 4 years, 0 months and 5 years, 0 months. Five children were excluded because they scored below $40 \%$ correct, and 3 children did not complete the session. The final sample included 48 children ( 20 male, 28 female) with a mean age of 4 years, 4 months ( $S D=1.2$ months).

Materials and Procedure. The materials and procedure of the first part of the experiment were identical to those of Experiment 1, except that every delay period was followed by one of two suffixes immediately before the picture stimuli. The experimenter either said the word "okay" as a suffix or produced a tongue cluck of approximately the same loudness. The tongue cluck was used because pilot data indicated that if the list and the nonspeech noise did not have the same source of origin, the children were distracted from the task. ${ }^{1}$ Finally, in order to avoid doubling the length of the session relative to the previous experiment, only the backward order of picture presentation was used. The same counterbalancing scheme was used as in the previous experiment, except that the speech versus nonspeech suffix variable was substituted for the forward versus backward picture order.

After the memory test phase an additional overt rehearsal phase was added to the procedure for half of the subjects, so that we could examine the assumption that the children are unable to rehearse dur- 
ing the silent delay periods. In this phase, children were trained to rehearse and the session was recorded on videotape. Picture sets and nonword syllables from the first three trials in the test phase were reused in this procedure, but this overt rehearsal phase did not include suffix stimuli.

Prior to any rehearsal training within this phase, one ordinary trial from the first part of the experiment was rerun and videotaped in order to assess the child's agility in the manual imitation task. This trial included a two-syllable list, a 15-sec delay with imitation of hand motions, and then the pictures in backward order. Next, the child was told that it would be fun to say some of the sounds aloud. At first the child was to repeat the syllables along with the experimenter. After he or she seemed to understand the task, the child received a one-syllable- and then a two-syllable rehearsal training trial, in which the syllables were to be repeated while the subject performed the manual task. During these initial training trials, the experimenter prompted the child whenever necessary. However, these trials were followed by two two-syllable trials of rehearsal testing in which there was no assistance from the experimenter. Only these unassisted trials were scored for rehearsal ability. Both of them included a $20-\mathrm{sec}$ delay period, but the analyses were restricted to the first $15 \mathrm{sec}$ of the delay for videotaped comparisons of manual imitation and picture selection with and without concurrent overt rehearsal.

\section{Results and Discussion}

Test phase. In an ANOVA of the percentage of correct picture selection with serial position (2), delay (4), and suffix type (2) as factors, performance levels were found to be significantly lower in the first serial position $(47.4 \%)$ than in the second serial position $(62.2 \%)$, $[F(1,47)=14.78, p<.001, \mathrm{SEM}=2.7 \%]$; performance levels decreased across delays [means $=65.6 \%$, $52.1 \%$, and $49.5 \%$ at the four delays; $F(3,141)=4.10$, $p<.01, \mathrm{SEM}=3.6 \%]$ and performance levels were higher with the nonspeech suffix $(62.2 \%)$ than with the speech suffix $(47.4 \%)[F(1,47)=24.99, p<.001$, $\mathrm{SEM}=2.1 \%]$.

There was also a significant interaction of serial position $\times$ suffix type $[F(1,47)=5.03, p<.03$, SEM $=3.6 \%$, and a three-way interaction of serial position $\times$ suffix type $\times$ delay $[F(3,141)=3.56, p<.02$, SEM $=6.3 \%]$. These effects are illustrated in Figure 2 . In the first serial position, there was a suffix effect at each delay, but in the final serial position, there was a suffix effect only with delays of 5 and $10 \mathrm{sec}$. In order to further examine these effects, separate analyses were conducted with the data from only the shortest two delays and the data from only the longest two delays. In the analysis for the shorter delays $(5$ and $10 \mathrm{sec})$, there were main effects of serial position $[F(1,47)=4.84, p<.04]$, delay $[F(1,47)=7.05, p<.02]$, and suffix type $[F(1,47)$ $=15.74, p<.001]$. However, there were no significant interactions. In contrast, in the analysis for the longer delays ( 15 and $20 \mathrm{sec}$ ), there were not only main effects for serial position $[F(1,47)=10.76, p<.002]$ and suffix type $[F(1,47)=5.29, p<.03]$, but also an interaction of serial position $\times$ suffix type $[F(1,47)=14.35, p<$ $.001]$. As Figure 2 indicates, there was no suffix effect in the last serial position after delays of 15 or $20 \mathrm{sec}$.

The discrepancy between the time course of the suffix effect at the initial versus the final serial position suggests that the speech memory code used to retain items in these serial positions differed. For example, items in the last serial position may have been retained partly with a sen-

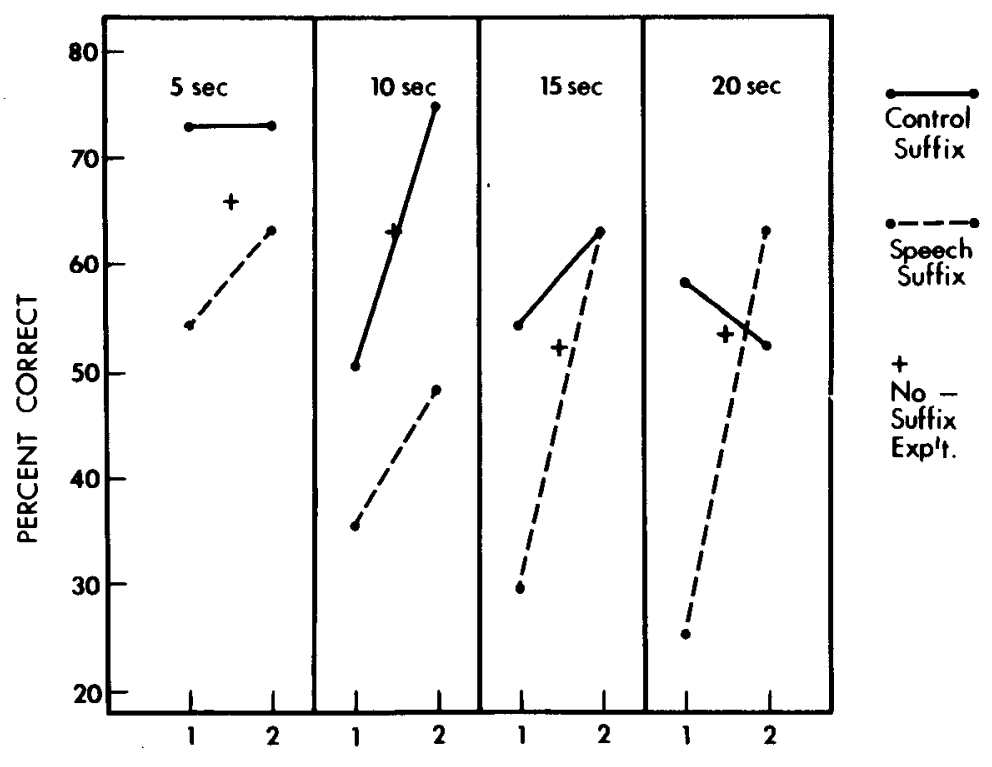

LIST ITEM

Figure 2. Percentage of correct picture selection at each delay and serial position for speech sumx trials (dashed lines) and control trials (solid lines) in Experiment 2. Data from Experiment 1 (crosses) included for comparison. Sumx effects of at least $18 \%$ were significant at $p<.05$; sufinx effects of at least $24 \%$ were significant at $p<.01$. 
sory code that decayed in about $10-15 \mathrm{sec}$. In contrast, items in the first serial position were held in a form that remained susceptible to speech interference even with a 20 -sec delay. For example, a short-term, phonetic/ articulatory code would be susceptible to interference (Campbell \& Dodd, 1980; Nairne \& Walters, 1983) and might last for $20 \mathrm{sec}$ or more.

It is not clear if the results at either serial position index the same type of memory that yielded a suffix effect with long delays in the experiments of $\mathbf{M}$. J. Watkins and Todres (1980). However, in any case, the data provide further support for their general conclusion that some form of auditory memory persists for a number of seconds (in the present study, at least $10 \mathrm{sec}$ ).

Overt rehearsal task. Finally, the results of the second phase of the experiment verified the assumption that children are unable to rehearse while performing the manual imitation task during the delay period. These data were analyzed on videotape by a rater who could not observe the child's picture selection. Each delay period was divided into 5-sec blocks, and in each block the child received two scores: one for the successfulness of manual imitation, and one for the successfulness of overt rehearsal. A score of 2 was assigned if performance was adequate within the 5-sec block; a score of 1 if performance was inaccurate or incomplete; and a score of 0 if the child failed (i.e., if there was a cessation of manual imitation or verbal rehearsal). Recoding of 480 observation intervals (based on the full $20 \mathrm{sec}$ for 120 trials) indicated a reliability of .92 .

When no overt rehearsal was required, the children received a perfect score for manual imitation in $98.6 \%$ of the 5-sec blocks. In striking contrast, in the final two test trials with overt rehearsal, children performed this manual task correctly only $\mathbf{4 2 . 4 \%}$ of the time. Thus, it is unlikely that children covertly performed a similar type of rehearsal in the present experiments. Moreover, in these final overt rehearsal trials, the children selected the correct pictures $52 \%$ of the time, a percentage that is approximately midway between the suffix and control performance levels for the 20-sec delay in the first test phase of the experiment. Thus, the children's attempts at overt rehearsal did not improve performance and may have produced some auditory interference.

Given the children's near-perfect performance on the manual task in the absence of rehearsal, it would be useful to learn the proportion of the time in which each child was able to perform the manual task and rehearse one or more of the speech stimuli at the same time. These data are given in Table 2, for $30 \mathrm{sec}$ of observation per subject in the two final trials. The table shows the number of observation intervals out of six in which each subject was able to perform the manual copying task and simultaneously carry out overt rehearsal. Each row sums to 24, the number of subjects receiving this task. The table indicates that for most children there was not even one 5sec period in which manual imitation was performed correctly and rehearsal was at least partly correct (see the
Table 2

Number of Observation Intervals of Success, Partial Success, and Failure at Overt Rehearsal During Successful and Unsuccessful Manual Performance

\begin{tabular}{|c|c|c|c|c|c|c|c|c|c|}
\hline \multicolumn{2}{|c|}{ Score } & \multicolumn{8}{|c|}{ Number of Observation Intervals* } \\
\hline Manual & Rehearsal & 0 & 1 & 2 & 3 & 4 & 5 & 6 & Total \\
\hline 2 & 2 & 15 & 3 & 4 & 1 & 0 & 0 & 1 & 24 \\
\hline 2 & 1 & 22 & 2 & 0 & 0 & 0 & 0 & 0 & 24 \\
\hline 2 & $\mathbf{0}$ & 13 & 2 & 3 & 2 & 1 & 0 & 3 & 24 \\
\hline 1 or 0 & 2 & 10 & 1 & 3 & 3 & 3 & 2 & 2 & 24 \\
\hline 1 or 0 & 1 or 0 & 11 & 2 & 4 & 4 & 2 & 0 & 1 & 24 \\
\hline
\end{tabular}

Note-A score of 2 denotes adequate performance; a score of 1 , flawed performance; and a score of 0 , failure to perform. Some categories are collapsed for the sake of simplicity. Rehearsal was adequate in 70 out of 144 observation intervals and manual imitation was adequate in 58, but both were adequate only in 20 intervals. *Each subject had two 15 -sec trial observations, divided into six 5 -sec observation intervals.

first two rows of the table). Recall also that the stimuli in these trials were employed here for the second time, and this added familiarity should have made the task easier than it would have been in the prior test phase of the experiment.

It was also possible to examine whether individual differences in overt rehearsal or manual copying were related to the number of items correctly identified. It was found that children who used the manual imitation task more consistently during overt rehearsal ${ }^{2}$ remembered fewer of the list items $[r=-0.41, t(22)=-2.12$, $p<.05]$. In contrast, the correlation between the amount of overt rehearsal and number of items correct was nonsignificant $(r=-0.15)$. When the number of correct items was compared to an overall "postlist interference score" obtained by summing each child's score for manual imitation and overt rehearsal, the resulting correlation was slightly more negative $[r=-0.46, t=-2.42, p<.05]$ than for manual imitation examined alone. Perhaps a slight mnemonic effect of rehearsal was more than offset by the auditory interference it caused. Finally, there was a negative relation between the child's ability to perform manual imitation and overt rehearsal $[r=-0.50, t(22)=-2.67$, $p<.02]$. This suggests that the two postlist activities required attention and were somewhat mutually exclusive for the children. The results of the overt rehearsal task strongly suggest that children could not have been rehearsing the stimuli during the silent delay periods following the spoken lists. This finding is reassuring for the present methodology. It is also interesting as a developmental phenomenon. In informal adult testing, adults consistently found it easy to perform manual imitation and overt verbal rehearsal simultaneously. Similarly, Guttentag (1984) found that there was a greater mental effort requirement of cumulative rehearsal (i.e., more interference from a concurrent motor task) for younger children than for older children.

\section{EXPERIMENT 3}

The main purpose of Experiment 3 was to examine the responses of adult subjects to the same stimuli ad- 
ministered to young children in Experiment 2. Additionally, this experiment included two manipulations to help specify the basis of any differences between children and adults observed. The first of these is the use of two different postlist distractor tasks. It seemed likely that the manual imitation task used with preschoolers would not prevent adults from engaging in verbal rehearsal. Therefore, half of the subjects in Experiment 3 received instead a silent arithmetic task. Second, a supplementary phase of the experiment was included in which the nonspeech suffix was a tone as is typically employed, rather than the tongue cluck used in the present experiments with preschool children.

\section{Method}

Subjects. The subjects were 48 normal young adults (18 male and 30 female) who participated in exchange for extra credit in an introductory psychology course.

Materials. In the first test phase of the experiment, the materials were identical to those used in Experiment 2. However, a supplementary phase additionally made use of a foot pedal that, when depressed, activated a $500-\mathrm{Hz}$ tone generated by a Maico audiometer through a Lloyd's WW009 speaker. The tone was set to be equivalent in loudness to the spoken list, approximately $70 \mathrm{~dB}(\mathrm{~A})$ at the subject's head.

Procedure. The training session was greatly shortened from the procedure used with preschool children. The subject was simply told that on each trial he/she would hear two nonsense syllables, after which there would be a task-filled delay period (manual imitation for some subjects and silent arithmetic for others) and then a final item (a tone, a tongue cluck, or the word "okay") that would serve as a signal that the delay period was over. Next, two sheets of pictures were to be introduced, one at a time, and the subject was to select those pictures whose names rhymed with the spoken syllables. Only one pair of picture sheets was used in training, but these pictures were used for three different training trials. For each of the training trials, a 6-sec delay filled with the distractor task was included. In the first training trial the speech suffix was used (with syllables rhyming with train and sled), in the second the tone was used (with syllables rhyming with $\log$ and gate), and in the third the tongue cluck was used (with syllables rhyming with tire and pear).

The manual imitation task used with half of the subjects was similar to that used with the preschool children, except that more subtle, detailed hand motions were included (e.g., touching the palm with the index finger of the other hand while bending both thumbs). For the remaining subjects, the silent arithmetic task was used instead: Upon completion of the spoken list, the experimenter would immediately hold up a three-digit number in bold lettering on a card $8.5 \times 18.5 \mathrm{~cm}$, and the subject was to repeatedly (and silently) subtract 3 from the number as quickly as possible, writing the answers on a blank piece of paper.

The stimuli and procedure of the first test phase were identical to those of the first test phase of Experiment 2, except for the differences in the distractor tasks. There was also a second test phase, but it was unrelated to the second (overt rehearsal) phase of Experiment 2. In this phase of Experiment 3, there were two trials with a speech suffix and two with a tone suffix in place of the tongue cluck used in the first phase. For each suffix, there was one trial with a 5-sec delay and one with a 20 -sec delay. The order of these four trials was determined by the order in which a particular subject had received stimuli in the first test phase. For example, if the speech trials were administered before the tongue cluck trials in Test Phase 1, then the speech trials were also administered before the tone trials in Test Phase 2, and if the 20-sec trials preceded the 5- sec trials in Test Phase 1, they did in Test Phase 2 also. The stimuli in Test Phase 2 were drawn from those that had been used in training trials for the preschool children that were unnecessary for adults. Every subject received the same sequence of syllables and pictures in this phase.

\section{Results and Discussion}

The mean percentages correct for the various conditions in Test Phase 1 are presented in the top half of Table 3 . The overriding conclusion from this table is that very few errors were made in any condition. Nevertheless, an ANOVA was carried out on the percent correct with distractor task (2) as a between-subject factor and serial position (2), postlist delay (4), and interference type (2) as within-subject factors. There was a significant interaction of serial position $\times$ delay $[F(3,138)=2.75$, $p<.05, \mathrm{SEM}=2.2 \%$, which occurred because there was a recency effect at the 5-sec delay only. There was also a three-way interaction of serial position $x$ delay $x$ interference type $[F(3,138)=3.44, p<.02$, $\mathrm{SEM}=2.6 \%$ ]. The pattern of results underlying this effect is quite unlike that of Experiment 2. There was no overall deterioration of performance across delays, and there was a possible suffix effect (i.e., performance with the tongue cluck suffix superior to that with the speech suffix) only with $15-$ and $20-\mathrm{sec}$ delays. However, a separate ANOVA for these two delays with the same factors as the overall analysis yielded no significant effects. There was no significant difference in any of the analyses between performance with a hand motion distractor $(95.3 \%)$ and silent arithmetic $(94.5 \%)[F(1,46)=.1]$, and no other effect in the overall analysis was significant.

The percentages correct for each condition in Test Phase 2, which included speech versus tone suffix conditions, are presented in the bottom half of Table 3. In an ANOVA with serial position (2), postlist delay (2), and interference type (2) as factors, there were no significant effects, although there was a marginally significant effect of delay $[F(1,46)=3.93, p<.051$, SEM $=1.8 \%]$. Thus, the absence of a suffix effect in Test Phase 1 cannot be attributed to the fact that the nonspeech suffix was a tongue cluck.

In summary, the overall high performance levels, the absence of significant delay effects, and the absence of

Table 3

Percentages of Correct Picture Selection by Adults in Experiment 3

\begin{tabular}{|c|c|c|c|c|c|c|c|c|}
\hline \multirow[b]{3}{*}{ Delay (sec) } & \multicolumn{4}{|c|}{ Hand Motion Group } & \multicolumn{4}{|c|}{ Silent Arithmetic Group } \\
\hline & \multicolumn{2}{|c|}{ Speech } & \multicolumn{2}{|c|}{ Cluck } & \multicolumn{2}{|c|}{ Speech } & \multicolumn{2}{|c|}{ Cluck } \\
\hline & SP1 & $\mathrm{SP} 2$ & SP1 & SP2 & SP1 & SP2 & SP1 & SP2 \\
\hline \multicolumn{9}{|c|}{ Test Phase 1} \\
\hline 5 & 95.8 & 100 & 95.8 & 100 & 83.3 & 100 & 91.7 & 100 \\
\hline 10 & 95.8 & 95.8 & 95.8 & 91.7 & 91.7 & 100 & 100 & 87.5 \\
\hline 15 & 95.8 & 95.8 & 95.8 & 100 & 95.8 & 87.5 & 95.8 & 95.8 \\
\hline 20 & 91.7 & 83.3 & 91.7 & 100 & 95.8 & 91.7 & 100 & 95.8 \\
\hline \multicolumn{9}{|c|}{ Test Phase 2} \\
\hline 5 & 91.7 & 100 & 95.8 & 95.8 & 95.8 & 91.7 & 100 & 95.8 \\
\hline 20 & 91.7 & 95.8 & 83.3 & 95.8 & 100 & 91.7 & 87.5 & 91.7 \\
\hline
\end{tabular}

Note-SP refers to serial position. * In Test Phase 2, the cluck was replaced by a tone 
significant suffix effects all are in strong contrast to the preschool data. It is clear from these data that adults either encoded or maintained the speech sounds in a way that preschool children did not. Moreover, the superiority of adult performance was equally great with the manual imitation and silent arithmetic distractor tasks. If the source of the adult advantage were the ability to rehearse the stimuli during the postlist delay, one would expect this advantage to be attenuated with the arithmetic task (which requires verbal processing). Instead, it seems more likely that the adult advantage occurs at the time of initial encoding of the stimuli or at the time of retrieval.

\section{EXPERIMENT 4}

Because the adult subjects in the previous experiment performed at a near-ceiling level, it is not possible to conclusively compare the patterns of performance of the preschool children with those of the adults. Therefore, another experiment was conducted with a more challenging set of stimulus conditions, but with a similar basic task. The most important modification was that each spoken list now included four syllables rather than two. Additionally, all subjects received the silent arithmetic distractor task, and the difficulty of this task was increased.

In the present experiment, the suffix was presented either immediately after the list (which should maximize interference) or after a $20-\mathrm{sec}$ delay. A condition was also included in which the 20-sec delay was presented after the suffix, to determine whether the suffix would eliminate the form of memory that decays over a $20-\mathrm{sec}$ period.

\section{Method}

Subjects. The subjects were 54 students of introductory psychology ( 22 male and 32 female) who participated in exchange for extra credit.

Materials. In the present experiment, four-syllable lists and the accompanying picture materials were constructed by regrouping the materials used in the previous experiments. The grouping resulted in one set of four picture pages to use in training, and six sets for the test phase. In order to produce enough materials, most of the pictures included in training for the preschool children were used in the test session within the present experiment.

Procedure. In this experiment, each list of syllables was spoken only once by the experimenter, at a rate of one syllable per second, as in Experiments 1-3. Subjects were taught to listen to the syllable lists, disregard the suffix item, perform the distractor task, and select one item whose name rhymed with a list item from each page of three pictures. The distractor task was to repeatedly subtract 7 from a three-digit number presented at the beginning of the delay period, as rapidly as possible (whereas in the previous experiment, the arithmetic task was to subtract 3 ). The pictures were always presented in a backward order relative to the spoken syllables.

There were three training trials using the same set of pictures, but with different spoken syllables. The first training trial included a speech suffix and no delay, the second included a tongue cluck and then a 10-sec delay, and the third included a 10-sec delay and then a speech suffix.

There were six trials in the test phase. Half of the subjects received three trials with a speech suffix and then three with a tongue cluck, whereas the remaining subjects received the trials with a tongue
Table 4

Percentages of Correct Picture Selection by Adults in Experiment 4

\begin{tabular}{lccccc}
\hline Delay Condition & SP1 & SP2 & SP3 & SP4 & Mean \\
\hline \multicolumn{5}{c}{ Speech Suffix } \\
Immediate & 79.6 & 77.8 & 88.9 & 88.9 & 83.8 \\
Suffix-20 sec & 70.4 & 59.3 & 68.5 & 79.6 & 69.4 \\
20 sec-Suffix & 68.5 & 64.8 & 66.7 & 81.5 & 70.4 \\
\multicolumn{5}{c}{ Tongue Cluck } \\
Immediate & 83.3 & 83.3 & 85.2 & 94.4 & 86.6 \\
Suffix-20 sec & 66.7 & 68.5 & 75.9 & 85.2 & 74.1 \\
20 sec-Suffix & 83.3 & 61.1 & 64.8 & 79.6 & 72.2 \\
& \multicolumn{5}{c}{} \\
All Delays & Mean, Both Suffix Conditions & \\
\hline
\end{tabular}

Note-SP refers to serial position.

cluck suffix first. Within each set of three trials, there was one with the suffix presented immediately and with no delay before the picture presentation, one trial with a suffix and then a $20-\sec$ delay, and one trial with a 20 -sec delay and then a suffix. These three trials were ordered according to one row of a Latin square, and the order was repeated for the second set of three trials.

\section{Results and Discussion}

The mean percentages of correct picture selection are presented in Table 4. In an ANOVA with serial position (4), delay condition (3), and interference type (2) as factors, the only significant effects were main effects of serial position $[F(3,159)=8.27, p<.001, \mathrm{SEM}=2.3 \%]$ and delay condition $[F(2,106)=13.82, p<.001, \mathrm{SEM}=$ $2.1 \%$ ]. The basis of the serial position effect was an overall advantage for syllables presented most recently in the spoken list. Separate analyses for two delay conditions at a time confirmed the impression from Table 4 that the delay effect occurred because there was a difference between the no-delay and suffix-then-delay conditions $[F(1,53)=17.59, p<.001]$ and between the no-delay and delay-then-suffix conditions $[F(1,53)=28.65, p<$ $.001]$, but no difference between the suffix-then-delay and delay-then-suffix conditions $[F(1,53)=.02]$. In none of these analyses was there a differential effect of the speech versus nonspeech suffix.

The present experiment differs in several ways from previous studies with adult subjects in which suffix effects have been obtained (e.g., Morton et al., 1971). First, in the present experiment only four items were included in each list, whereas more items have been used in previous studies. Second, in the present study the subjects' task was to recognize pictured items rather than to recall items. With the contextual support provided by the picture stimuli, adults may have been able to make better use of remaining speech memory. Supporting this interpretation, Parkinson (1978) obtained suffix effects with a recall task but not with a recognition task.

\section{GENERAL DISCUSSION}

For both preschool children and adults within the present study, retention of a list of spoken syllables 
decreased across a postlist delay of up to $20 \mathrm{sec}$ when sufficient list lengths were used (two-syllable lists for preschool children and four-syllable lists for adults). However, selective interference from a speech suffix was obtained under the present task constraints only in preschool children. Moreover, the magnitudes of these suffix effects in preschool children (over $30 \%$ in some conditions) were large compared to what is typically observed in adult studies of the suffix effect (10\%-20\%).

The absence of suffix effects in adults using the present task, which involves recognition, is consistent with Parkinson's (1978) finding of no suffix effects in adults with a recognition paradigm. However, the presence of large suffix effects in preschool children using this same task suggests that adults perform some type of speech coding that provides immunity to the suffix effect, and that preschool children are not capable of carrying out this coding under the present task constraints. This coding in adults could occur during the initial reception of the speech stimuli (e.g., adults might generate an orthographic code or an abstract phonological code) or it could occur during the response period (e.g., the process of covertly naming the picture stimuli might help to restore a fading speech memory more effectively in adults). However, the extra coding that adults carry out is unlikely to occur during the silent delay period, given that adults performed demanding distractor tasks during this period. Another type of evidence that there is a developmental change in speech coding is Hulme's (1984) finding that in older children, unlike preschool children, memory for a list of words is affected by the phonological similarity of words within the list, as well as Conrad's (1971) earlier demonstration of a similar effect using picture stimuli with phonologically similar or dissimilar names rather than spoken words.

The suffix effect in preschool children was obtained at all delays $(5,10,15$, and $20 \mathrm{sec})$ for the first serial position in two-syllable lists, but only after 5- and 10-sec postlist delays for the second serial position. Thus, there was a dissociation between two forms of memory for speech susceptible to speech interference, with a different distribution across serial positions. (Moreover, the time course of the suffix effect at the final serial position was consistent with the delay effects obtained in Experiment 1 and in the control-suffix condition of Experiment 2, as shown in the figures). Although the characteristics of these two forms of memory are uncertain, it is possible that children used predominantly an articulatory memory at the first serial position and an auditory sensory memory at the final serial position. Prior research is consistent with this possibility. Specifically, only the final list item provides a relatively pure index of auditory sensory memory (Balota \& Engle, 1981; Greenberg \& Engle, 1983), whereas articulatory memory is not localized in this way (Cheng, 1974).

Why did the suffix effect in the final serial position occur only at the 5- and 10-sec delays? According to the logic of M. J. Watkins and Todres (1980), there are at least two possibilities. First, the form of memory interfered with may have decayed within $15 \mathrm{sec}$. Alternatively, children could form a suffix-resistant store for the final item across roughly the first $10 \mathrm{sec}$ of the delay period, obscuring any subsequent effect of the speech suffix. However, it is difficult to understand how children could accomplish this abstract coding over such a long period while engaged in a manual imitation task. Consequently, the suffix results may be taken as evidence (along with the delay effects) that there is a form of memory for speech that decays in 10-15 sec in preschool children. This form of memory might be comparable to the memory observed by Watkins and Todres (1980) and Balota and Duchek (in press) across a 20-sec period in adult subjects. There may or may not be a developmental change in the duration of various forms of speech memory (cf. Dempster \& Rohwer, 1983; Engle, Fidler, \& Reynolds, 1981; Frank \& Rabinovitch, 1974).

\section{REFERENCES}

Balota, D. A., \& Duchek, J. M. (in press). Voice-specific information and the 20-second delayed suffix effect. Journal of Experimental Psychology: Learning, Memory, \& Cognition.

BAlota, D. A., \& ENGLE, R. W. (1981). Structural and strategic factors in the stimulus suffix effect. Journal of Verbal Learning \& Verbal Behavior, 20, 346-357.

Bradley, L, Bryant, P. E. (1983). Categorizing sounds and learning to read-A causal connection. Nature, 301, 419-421.

Campbell, R., \& DodD, B. (1980). Hearing by eye. Quarterly Jour nal of Experimental Psychology, 32, 85-99.

Cheng, C. (1974). Different roles of acoustic and articulatory information in short-term memory. Journal of Experimental Psychology, $103,614-618$.

Conrad, R. (1971). The chronology of the development of covert speech in children. Developmental Psychology, 5, 398-405.

Cowan, N. (1984). On short and long auditory stores. Psychological Bulletin, 96, 341-370.

Crowder, R. G. (1971). Waiting for the stimulus suffix: Decay, delay, rhythm, and readout in immediate memory. Quarterly Journal of Experimental Psychology, 23, 324-340.

Crowder, R. G. (1983). The purity of auditory memory. Philosophical Transactions of the Royal Society of London, B302, 251-265.

Crowder, R. G., \& Morton, J. (1969). Precategorical acoustic storage. Perception \& Psychophysics, 5, 365-373.

DEMPSTER, F. N., RoHWER, W. D. (1983). Age differences and modality effects in immediate and final free recall. Child Development, 54, 30-41.

Engle, R. M., Fidler, D. S., \&eynolds, L. H. (1981). Does echoic memory develop? Journal of Experimental Child Psychology, 32, 459-473.

Flavell, J. M., Beach, D. R., * Chinsky, J. M. (1966). Spontaneous verbal rehearsal in a memory task as a function of age. Child Development, 37, 283-299.

Frank, H. S., \& Rabinovitch, M. S. (1974). Auditory short-term memory: Developmental changes in precategorical storage. Child Development, 45, 522-526.

GREENBERG, S. N., ENGLE, R. W. (1983). Voice changes in the stimulus suffix effect: Are the effects structural or strategic? Memory \& Cognition, 11, 551-556.

GUTTENTAG, R. E. (1984). The mental effort requirement of cumulative rehearsal: A developmental study. Journal of Experimental Child Psychology, 37, 92-106.

Hulme, C. (1984). Developmental differences in the effects of acoustic similarity on memory span. Developmental Psychology, 20, $650-652$. 
KAIL, R., HAGEN, J. W. (1982). Memory in childhood. In B. B. Wolman (Ed.), Handbook of developmental psychology. Englewood Cliffs, NJ: Prentice-Hall.

KuCZAJ, S. A., II. (1979). Evidence of a language learning strategy: On the relative ease of acquisition of prefixes and suffixes. Child $D e-$ velopment, 50, 1-13.

Morton, J., Crowder, R. G., \& Prussin, H. A. (1971). Experiments with the stimulus suffix effect. Joumal of Experimental Psychology, 91, 169-190.

NaIRNE, J. S., \& WALTERS, V. L. (1983). Silent mouthing produces modality- and suffix-like effects. Journal of Verbal Learning \& Verbal Behavior, 22, 475-483.

PARKINSON, S. R. (1978). An alternative interpretation of the stimulus suffix effect. Journal of Experimental Psychology: Human Learning \& Memory, 4, 362-369.

Penney, C. G. (1985). Elimination of the suffix effect on preterminal list items with unpredictable list length: Evidence for a dual model of suffix effects. Joumal of Experimental Psychology: Learning, Memory, \& Cognition, 11, 229-247.

Tallal, P., Stark, R., Kallman, C., Mellits, D. (1981). A reexamination of some nonverbal perceptual abilities of language-impaired and normal children as a function of age and sensory modality. Journal of Speech \& Hearing Research, 24, 351-357.

WatKINS, M. J., \& TodreS, A. K. (1980). Suffix effects manifest and concealed: Further evidence for a 20-second echo. Journal of Verbal Learning \& Verbal Behavior, 19, 46-53.
Watkins, O. C., WatKINS, M. J. (1980). The modality effect and echoic persistence. Journal of Experimental Psychology: General, 109, 251-278.

\section{NOTES}

1. Young children in pilot sessions were found not to respond well to taped presentation of the spoken stimuli. Consequently, in order to use a tone suffix, a separate tone generator was necessary. However, when a tone suffix was used with pilot subjects, they performed more poorly than they did in the speech suffix condition, and they often searched for the tone generator or turned toward it. Therefore, the tongue cluck was used instead as a nonspeech noise that came from the same source as the speech suffix and the list. Inasmuch as the amount of interference from a suffix depends upon the acoustic similarity of the list and suffix (Morton et al., 1971), the tongue cluck should serve as an adequate control with which to compare the acoustically more similar speech suffix.

2 . The measure employed was the sum of scores $(0,1$, and 2$)$ across the eight observation periods within the two overt rehearsal test trials combined.

(Manuscript received October 3, 1985; revision accepted for publication April 4, 1986.) 